\title{
The Application of Biotechnology on Livestock Feed Improvement
}

\author{
Mebrate Getabalew ${ }^{1}$ and Tewodros Alemneh ${ }^{2 *}$ \\ ${ }^{1}$ Department of Animal Science, College of Agricultural and Natural Resource Science, Ethiopia \\ ${ }^{2}$ Department of Agriculture and Environmental Protection, South Gondar Zone, Amhara Regional State, Ethiopia
}

*Corresponding author: Tewodros Alemneh, Woreta City Office of Agriculture and Environmental Protection, South Gondar Zone, Amhara Regional State, Ethiopia, Email: tedyshow@gmail.com.

\author{
Received Date: May 22, 2019 \\ Published Date: May 24, 2019
}

\begin{abstract}
Biotechnology has a role on animal feed improvement in three main ways, those are: value-addition to forage used as animal feed, production of feed additives and the manipulation of rumen microbes to improve feed utilization. Know a day; there is shortage of animal feed in most parts of the world, and an increasing in the price of feed ingredients, which is an indicative of improving feed utilization. The developing world accounts majority of the world's human population. Due to this fact, biotechnology has a key role in livestock feed improvement in order to fulfill the requirements of animals as well as human beings. Many of the biotechnological techniques can be employed in the area of quality assurance programs, which would be of great importance to produce livestock products of assured quality and public health safety. Monogastric animals, like pig and poultry, are unable to digest poor quality feeds unlike ruminant animals. Such animals need biotechnology to improve the nutritive value of poor-quality feed and its ability to digest fibers. As a result, the productive and reproductive performance of those livestock used biotechnological feeds become higher. Therefore, the objective of this review is to investigate the role or application of biotechnology on livestock feed improvement.
\end{abstract}

Keywords: Biotechnology; Livestock; Feed improvement; Rumen microbes; Monogastric animals

\section{Introduction}

Today demand for livestock products are becomes increasing because of the increasing world human population, income growth and increase of urbanization [1]. For example, total meat production in the developing world was tripled between 1980 and 2002, from 45 to 134 million tons. Demand for meat will grow only $0.6 \%$ in developed world compared with an annual increase of $2.8 \%$ in developing world. Most food of animal origin consumed in developing countries is currently supplied by small-scale and mixed crop-livestock producer or by pastoral livestock keepers by producing in traditional way [2].

Traditional methods of livestock improvement have been used in the past year and served the purpose of increasing livestock productivity for meeting the requirement of the world. But this method can no longer sustain production; consequently, new intensive techniques including biotechnology are now required to increase productivity of animals by using different alternatives. Today, biotechnology has able to provide new opportunities for meeting enhanced livestock productivity in a way that alleviates poverty, improves food security and nutrition and promotes sustainable use of natural resources [3].

In animal feed, biotechnology can improve the plane of nutrition through protection of protein, amino acids [4] and fat [5]. Use of enzymes to improve the availability of nutrients from available feed and to reduce the wastage of the feed, prebiotics and probiotics to inhibit enteric pathogenic bacteria, use of plant biotechnology to produce feed and fodder with good nutritive values can be done, genetic manipulation of rumen microbes to improve the animal health.

Animal feed and feeding practices are being changed by biotechnology to improve animal nutrition and to reduce environmental waste. The objective of using biotechnology in animal nutrition is to improve the plane of nutrition through the use of enzymes to improve the availability of nutrient from feed and to reduce the wastage of feed [6]. Improvements have largely come 
from dilution of maintenance [7], while other improvements can come from increased digestibility or nutrient availability from feeds, reduced non-productive days for dairy $[8,9]$ or genetic selection for feed efficiency [10]. Therefore, the objective of this work is to review the role or application of biotechnology on livestock feed improvements.

\section{Biotechnology: General Aspects}

Biotechnology has important roles in many ways because the world is to respond to the increasing demand for more food from livestock products due to rapid population growth and also income growth. Biotechnology in livestock production has its own role and can be categorized into three, which are biological, chemical and physical techniques that influence animal health, nutrition, breeding and reproduction [11]. These techniques have been applied mostly in developed world like USA, Brazil and others, but its application in Africa and Asia is minimal due to many reasons related to economic factors such as poor infrastructure, technical and educational capacity.

Today, livestock is becoming increasingly important to economic growth in developing world and the application of biotechnology is largely applied by commercial considerations and socio-economic goals. It will provide new and unexpected opportunities to improve the productivity of animals through increased growth, carcass quality and reproduction, improved nutrition and feed utilization also, improved quality and safety of animal feed, improved health and welfare of animals, and reduced waste through more efficient utilization of resources [12].

\section{Biotechnology in animal nutrition}

The major role of biotechnology on livestock production is increasing the livestock feeds through improving nutrient content / value as well as the digestibility of low-quality feeds like roughage through use of different chemicals for example feed additives. In animal nutrition, biotechnology can improve the plane of nutrition through protection of protein, amino acids [4] and fat [5]. Use of different enzymes to exploit the availability of nutrients from feed and to reduce the wastage of the feed and fodder, immune supplements to inhibit pathogenic bacteria to the animals, use of plant biotechnology to produce feed and fodder with good nutritive values, addition of antibodies in feeds can be used to protect the animals from the disease, genetic manipulation of rumen microorganisms to improve the animal health and growth.

\section{How biotechnology improve fibrous feeds}

Fibrous feeds of low digestibility account the major proportion of feeds accessible to most ruminants' animals under smallholder farmers in developing countries including Ethiopia. It is known that some microbes, including cellulose enzymes from anaerobic bacteria and white rot fungi (Pleurotus ostreatus) can degrade lignin in the cell walls of fibrous feed. Several fungal strains have been used for lingo cellulosic hydrolysis like, Asprigullus niger, A. terreus, Fusarium moniliforme and Chaetomium celluloyticum. But, from many species of fungi white rot fungi have been reported to be suitable for treatment of fibrous feed so far than others. As in the white rot fungi have the capacity to attack lignin polymers, open aromatic rings and release low molecular weight fragments [13].

\section{Role of biotechnologies for gut microbes}

Biotechnology can be mostly used for improving metabolism and activity of gut microorganism, which is very important for animal health and growth. This can be done in three different ways. The first one is the introduction of biotechnogical products to improve the gut ecosystem and promote the growth of beneficial bacteria/ microbe. The second one is to genetically modify microorganisms naturally present in the gut to enhance their capacity of defined functions. Introductions of diverse genes into gut microorganisms have been extensively explored [14]. The genetically modified microbes have the ability either to digest fibrous components and lignin of forages, to degrade toxins, to synthesize essential amino acids, to reduce methane formation, or to tolerate acids. The third way is to introduce new species or strains of microbes into the gut [15]. This application has a great potential than the two listed above to increase digestibility of feedstuffs and to improve animal health and growth.

Like introduction of Probiotics, they are live microbial feed supplements which beneficially affect the host by improving its intestinal microbial balance [16]. Correspondingly, in feed regulation, probiotics are included in the group of feed additives for stabilizing the microbial communities of the digestive tract in monogastric animals and ruminants. The commercial use of probiotics in the livestock industry, especially poultry, is relatively new. Only within the last few years have research workers documented the results of incorporating probiotics into poultry diets [12].

\section{Biotechnology products for feed additives}

Feed additives are materials which are introduced to the animal feed to increase the effectiveness of nutrients and exert their effects in the digestive tract of animals. It includes antibiotic, enzymes probiotics and prebiotics, and others [17].

\section{Antibiotics}

The major use of these antibiotics is for the treatment of infections, certain antibiotics are used as feed additives in order to improve growth and feed conversion efficiency of the animals. Among antibiotic groups are ionophores [17]. Ionophores are used in ruminant animals like cattle to improve feed efficiency by shifting rumen fermentation towards the production of more propionic acid, which can be used by the animal and less methane, which is lost. Ionophores hereby change the pattern of rumen microorganisms, reducing the production of acetate, butyrate and methane, and increasing the proportion of propionate $[17,18]$.

As indicated in [18], ionophores have general metabolic role within the animal through improving production efficiency by providing a competitive advantage for certain microbes at the expense of others. In another report, broilers chicken receiving 
the diet added with antibiotic had significantly lower total aerobic bacterial number in the small intestines as compared to those on the other dietary treatments. The combined supplementation of the antibiotic and enzyme resulted in a significantly lower E. coli concentration in the small intestines compared to the energy diet and the other dietary treatments [19].

\section{Enzymes}

By the aid of biotechnology, more effective enzyme preparations can now be produced in large amount and relatively inexpensively [17]. Therefore, supplementation of these enzymes as a means of improving nutritive value is becoming commonplace. Their major purpose is to improve the nutritive value of available diets, especially when poor-quality like, roughage and usually less expensive, ingredients is incorporated. Amino acid digestibility is improved with phytase enzyme supplementation. Cellulase enzymes can be used to break down cellulose, which is not degraded by endogenous mammalian enzymes. Enzymes are essential for the breakdown of cell-wall carbohydrates to release the sugars necessary for the growth of the lactic acid bacteria. Supplementation of a wheat byproduct diet with cellulase increased the digestibility of non-starch polysaccharides from 0.192 to 0.359 and crude protein from 0.65 to 0.71 [17].

\section{Probiotics and prebiotics feed additives}

They are feed supplements that can be added to the available diet of farm animals to improve intestinal microbial balance. In contrast to the use of antibiotics as nutritional modifiers, which eliminate bacteria, the inclusion of probiotics in foods is designed to encourage certain strains of bacteria in the gut at the expense of less desirable ones [17]. In ruminants, they are more and more effective in controlling the diseases of the gastrointestinal tract of young animals, as there is no complication of the rumen microflora. Adding of probiotics to the diet produces variable benefit, depending on whether the animals are in poor health. It is also difficult to determine which bacterial species would be beneficial in any given circumstance. In adult ruminants' yeasts may be used as probiotics to improve rumen fermentation. The most common prebiotics are oligosaccharides, which are non-digestible carbohydrates [3].

\section{Genetically modified rumen microbes}

With regard to fiber degradation in the rumen, much effort has been expended in developing genetically modified bacteria that would have superior fiber-degrading abilities that the naturally habitant in the rumen. It is well established that the principal fibrolytic bacteria of rumen are Ruminococcus and Fibrobacter, but it is thought that they do not produce exocellulases that are active against crystalline cellulose, so adding this activity would make them more potent. Ruminal bacterial species such as Butyrivibrio fibrisolvens and Prevotella ruminicola are found widely in ruminant animals on varied diets and are found in huge numbers regardless of the ruminal environment [12].

\section{Reintroduction of natural and genetically modified microbes to the rumen}

The ecology of the introduced strains has been overlooked to a large degree and the success of this technology may ultimately depend on a better understanding of factors that determine establishment in a complex microbial ecosystem, fermenting microorganisms [20]. Krause et al. [20]. found that re-establishment of either natural or recombinant ruminal bacteria in the rumen is both variable and unpredictable and there are even reports of the disappearance of the inoculant from the rumen after very short time period [21].

\section{Protection of protein, amino acids and fat}

Rumen enzymes break the protein to produce ammonia and then the ruminal microbes use this non-proteinous nitrogen to synthesize the microbial protein. To increase the utilization of degradable protein, it should be protected from ruminal degradation through chemical treatments such as formaldehyde and physical treatments like heat treatment and extrusion cooking. Some researchers have reported 33\% reduction in protein degradability by formaldehyde treatment of groundnut cake. Fat can be protected using the saponification of fat with calcium salts. Feeding calcium soaps of fatty acids, which are inert in rumen, to negative energy balance animals, enhances dietary energy density and thus, energy intake without compromising the activity of rumen microflora. Thus, the deleterious effect of negative energy balance on animals can be alleviated [12].

\section{The rumen and its microorganisms}

Ruminant animals have the ability to the utilization of forages depends on microbial fermentative digestion in the rumen; the principles of digestion in the rumen are discussed as a framework to view the requirements for biotechnology innovations in nutrition. The rumen is the dominant feature of the digestive tract of ruminants it accounts around $80 \%$ of the stomach. This is the medium that supports a dense and varied population of microorganisms. These organisms ferment feed materials to produce mainly short chain organic acids (VFAs), methane and carbon dioxide and the process provides substrate and energy for the growth of micro-organisms. The microbial mix in the rumen is complex and highly dependent on diet. The main agents that break down fiber, sugars, starches and proteins in the rumen are all anaerobic and include bacteria, protozoa and fungi [12].

\section{Protein utilization by ruminants}

More of protein is fermented in the rumen part largely wasted as a source of amino acids to the animal because dietary protein is degraded, and essential amino acids are deaminated to form ammonia and volatile fatty acids. Let see fermentation of $1 \mathrm{~g}$ of protein generates only half the energy (ATP) that would be produced from $1 \mathrm{~g}$ of carbohydrate and therefore anaerobic microbial growth on protein is approximately half that on carbohydrate. In combination, these effects result in only 30 to $60 \mathrm{~g}$ of microbial 
protein becoming available to the animal for digestion for every kilogram of dietary protein that is fermented in the rumen [12].

The fermentation of protein is, however, related with relatively small quantity of methane production. In the other hand methane is not generated when protein bypasses the rumen. Protein that is insoluble, or has a high component of disulphide bonds or is associated with tannins tends to bypass rumen fermentation but is digested in the intestines and in this way it produces the microbial protein and alters the ratio of protein to energy $(\mathrm{P} / \mathrm{E})$ in the nutrients absorbed [22].

\section{Mineral requirements of rumen microbes}

The rumen microbe needs both macro and micro minerals to meet the needs of structural components of cells and for components of enzymes and co-factors. As with any deficiency of a nutrient the likely scenario of a mineral deficiency for rumen organisms is first a reduced growth efficiency of microbes with or without a decrease the digestibility of the feed [23]. When the deficiencies become more extreme the digestibility of forage must decrease along with the decrease in microbial pool size and it is only then that feed intake will decrease. Feed intake, however, will be decreased as protein to energy ratio becoming to decreases if the animal is heat stressed [23].

\section{Genetically modified crops with improved amino acid profiles}

Genetically modified crops mean that crops which have great potential to decrease nitrogen excretion in poultry. Nitrogen can contaminate ground and surface waters; contribute to acid rains, which increase the acids in soils. Increased levels of essential amino acids like lysine, methionine, tryptophan, threonine in grains would mean that the essential amino acid requirement of poultry can be met with lower protein diets. Feeding these genetically modified crops varieties would reduce the amount of nitrogen in the form of urea from being excreted into the environment [24].

Genetically modified plants are produced by transferring of foreign genes of particular characteristics into other crops. For instance, introducing antibiotic resistant marker genes may render common infectious diseases untreatable or certain proteins may cause allergic reactions to animals and humans. Hence proper laboratory, field assessments as well as health assessments have to be made before release of such plants for commercial cultivation [24].

\section{Some Roles of Biotechnology in Feed Improvement Increasing digestibility of low-quality forages}

Know a day low-quality forages are a major feed component of ruminant diets in most of the world. Thus, much progress can be made by improving their quality by different way. The characteristic feature of tropical forages is their slow rate of microbial breakdown in the rumen with the result that much of the nutrients of the feed are voided in the faces. This results in reduced outflow rate of feed residues from the rumen which consequently depresses feed intake of the animal [25]. At present, the main treatment methods for low quality forages such as cereal straws are either mechanical like, grinding, physical like, temperature and pressure treatment or a range of chemical treatments. The lignifications of the cell walls prevent degradation feed by cellulase enzymes.

\section{Improving nutritive value of cereals}

According to Scott et al. [26], moderate protein content and low amounts of specific amino acids limit the nutritive value of cereals and cereal by-products. This is a major disadvantage in the ration formulation for non-ruminant livestock which necessitates addition of expensive protein supplements. There are on-going studies to enhance the low level of lysine in barley by genetically engineering the grain genome. Genetic modification through insertion of genes into rice protoplasts and generation of transformed plants has already been achieved.

\section{Removing anti-nutritive factors from available feeds}

Anti-nutritive factors in plant tissues like, protease inhibitors, tannins, and cyanogens in legumes, and glucosinolates, tannins and sanapine in oilseed rape and other compounds in feeds. As with amino acid deficiencies, the adverse effects of these compounds are more marked in non-ruminants than in ruminants. Conventional plant breeding has been used to reduce and, in some cases, eliminate such anti-nutritive factors from the feed. An example is the introduction of cultivars of oilseed rape which are low in, or free from erucic acid and glucosinolates. A combination of genetic engineering and conventional plant breeding should lead to substantial reduction or removal of the major anti-nutritive factors in plant species of importance as animal feeds [27].

\section{Improving nutritive value of conserved feed}

The conservation of plant material as silage depends upon anaerobic fermentation of sugars in the material which in turn is influenced by the ability of naturally occurring lactic acid bacteria to grow rapidly on the available nutrients under the existing environment. Other ways the ensiled material is sterilized, lactic acid bacteria are always present. However, the ensiling conditions may not always be ideal for their development. In addition to the number and type of bacteria, other factors may affect quality of conserved silage, like, availability of water-soluble carbohydrates, the dry-matter content, the $\mathrm{pH}$, etc. Let's take an example; lack of water-soluble carbohydrates may be overcome by wilting the material to raise the dry matter to a level at which less acid is required to stabilize the fermentation [26].

\section{Improving rumen function}

Malmuthuge and Guan [28] reviewed the major areas of rumen roles which might benefit from transgenic technology. These include development of transgenic bacteria with enhanced cellulotic activity, able to cleave lingo hemicellulose complexes, reduced methane production capability, increased capacity for nitrogen "fixation" and increased ability for microbial production of specific amino acids. But we are still a long way from commercial 
production of genetically engineered rumen bacteria; advances being made in transformation methods for obligate anaerobic bacteria will certainly result in successful genetic engineering of a range of rumen bacteria.

\section{Effects on microbial population and ruminal functions}

Yeast cultures are very important in the rumen. Different studies showed positive effects of yeast culture not only on the rumen environment, but also on the improvement of microbial activities. Yeast supplements imitate the growth of beneficial microorganisms in the rumen. For example, the numbers of total ruminal anaerobes and cellulolytic bacteria have been increased with yeast culture [29]. In this way, they influence the rate of volatile fatty acid production and, thus, increase the stability of rumen environment and improve the intensity of digestion.

\section{Metabolic modifiers}

Metabolic modifiers like, recombinant bovine somatotropin have been used to increase efficiency of production such as weight gain, improve carcass composition, researchers have also developed porcine somatotropin that increases muscle growth and reduces body-fat deposition, resulting in swine that are leaner and of greater market value metabolic modifiers are a group of compounds that modify animal metabolism in specific and directed ways. They have the overall effect of improving productive efficiency (weight gain or milk yield per feed unit) improving carcass composition (lean to fat ratio) in growing animals, increasing milk yield in lactating animals and decreasing animal waste per production unit [12].

\section{Biotechnology in Monogastric Nutrition}

Most developing world is facing difficulties of providing sufficient food for their own population. In general, in most third world countries food production is increasing at a slower rate than the population growth rate. Developing world on average are increasing food imports by $10 \%$ per year. This indicates this may continue into the future [12], whilst ruminant animals need not compete with humans for food. There are few economic, large scale systems for pig and poultry production established in developing world which does not rely on grain-based concentrate such as potatoes and other root crops which also take up land that could potentially be used for human food production.

Pigs have the ability to utilize some fibrous feed, up to $30 \%$ of their digestible feed intake because of the caecal fermentation in large intestine. It appears desirable that in the future, pig production should utilize at least a proportion of fibrous carbohydrate. Freerange pig production, where breeding stock obtain a fair proportion of their feed from pastures is a good beginning forced on producers in Europe by the high cost of grain feeding in intensive fattening systems [12].

\section{Potential areas for biotechnology in pig nutrition}

The use of oil-seed protein residues for pigs and poultry are generally very limited because of the fibrous components and in sometimes there is a secondary plant compound which may be toxic or simply reduce production (e.g. gossypol in cottonseed meal). To avoid the constraint created by too much fiber it may be possible to develop pre-treatment to protect the protein and then find mechanisms for decreasing the fiber [30].

\section{Non-cereal feed resources for pig}

The most alternatives to cereal grains for intensive feeding of pigs in the tropics are: sugar cane juice, sugar cane molasses, and juice from the sugar palm tree, oil, whole fruit and by-products of the African oil palm cassava roots and by-products and organic waste from urban households, restaurants and canteens. There are also other products and by-products from tree, root and tuber crops are included in tropical pig diets [31].

\section{Biotechnology derivatives for poultry feed}

Research which takes twenty years ago in Cuba indicated that raw sugar could replace the cereal grain in diets for all classes of poultry. But the technology never became truly commercial, because raw sugar is almost always too expensive to use in animal feeds. Molasses and cane juice are economically competitive with cereals, but there are many factors that against their use for fattening and laying birds [32]. For example: large scale poultry production system is designed to use complete mixed and dry diets. The productive life of broilers is too short ( 45 days) to permit them to adapt adequately to liquid diets. The mouth part of the chicken is not designed for consuming liquid feeds, etc.

\section{Laying and fattening hens}

Use of the cane juice in steady of grain in broiler and laying chicken diets doesn't successful due to the physical difficulties experienced by chickens in consuming a low-density liquid diet, and the stress caused by splashing of the sugar-rich juice on the feathers which can lead to cannibalism. Laying hens, particularly the heavier dual purpose strains, which have been raised on cane juice, have been maintained through complete laying cycles with satisfactory [33]. The hens tend to become fat during conventional feeding. If you receive a fiber-rich, nutrient-reduced feed, your body fat content will be significantly lower, and the laying performance of the hen will be better. As the feed used is less expensive, it reduces the losses caused by the inferior egg yield compared to conventional laying lines [33].

\section{Modifying the digestive function through development of transgenic animals}

By using their hindgut fermentation, pigs have the ability of digesting plant structural polysaccharides. In theory, substantially more energy would be available to pigs if cellulose and hemicellulose could be digested in the small intestine and the sugars absorbed. In addition, the complex carbohydrates of grains, fibrous protein sources could be more efficiently used. In the latter case it would allow a much higher proportion of protein from such sources to be incorporated into the diets replacing more expensive less fibrous protein meals such as fish or meat meal [34].

The ability to digest cellulose and hemicellulose by intestinal enzymes is not present in any animal. However, if introducing a gene for microbial cellulase or hemicellulase could be incorporated 
into an animal's genome and expressed in the pancreas it may allow these enzymes to be produced and secreted along with the other pancreatic secretions. This is being tested by Hazelwood and Gilbert [35] by introducing into the early embryo of mice the gene of Clostridium thermocellum which encodes a thermostable endogluconase with xylan-hydrolysing activity. Expressions of this gene in transgenic mice will be regulated by the elastase I promoter/enhancer region (from rats) which is located "upstream" of the elastase gene and is responsible for restricting the synthesis of the digestive enzyme elastase to target sites of expression of other genes, to the exocrine enhancer cells in the pancreas of transgenic mice [12].

To increase porcine digestive enzyme secretion to include the enzymes, cellulase and hemicellulase, will need tissue specific expression of the gene and secretion of mature active endogluconase enzyme into the intestinal lumen. By this reason gene constructs incorporating the elastase promoter/enhancer and coding sequence have been designed. Fiber breakdown in the pig by cellulose enzyme is likely to be slow and therefore gut capacity is likely to be a major constraint even when transgenic pigs are produced [34].

\section{Conclusion}

It can be concluded that there are several potential opportunities for improving the efficiency of ruminant digestion and possibilities for utilizing a wider range of feeds than is currently possible. Genebased technologies are being increasingly used to improve animal nutrition, through conservation of feed stuff in a form that keep or even improve its nutrients. Adopting biotechnology has benefitted by in animal improvement and economic returns to the livestock entrepreneurs and small producers. Fibrous feeds, including crop residues, of low digestibility constitute the major proportion of feeds available to most ruminants under smallholder situations in developing world. So, this is the time, when investment in biotechnology and animal nutrition is important for sustainability of human and animals, food security and wealth creation and used for poverty reduction of poor people living in the villages.

Therefore, the following recommendations can be made: in many countries and regions as possible, put major emphasis on local research to manipulate through feeding technology of the microbial ecosystem of the rumen and the animal's metabolism to make ruminants efficient on feeds that are locally available. The most important thing is the introduction of supplements to the available feed resources at poor quality feed in order to improve its nutritional value. Modern biotechnologies should also be developed worldwide.

\section{Acknowledgment}

Author's deepest gratitude goes to friends and Debre Berhan University communities for their material and logistic supports.

\section{Conflicting of Interests}

Authors declare that no any conflicting of interests.

\section{References}

1. Thornton PK (2010) Review livestock production: recent trends, future prospects. Phil Trans R Soc B 365(1554): 2853-2867.

2. John R, Maria Z, (2001) Report of the first six email conferences of the FAO Electronic Forum on Biotechnology in Food and Agriculture.

3. Bimrew A (2014) Biotechnological Advances for Animal Nutrition and Feed Improvement. World Journal of Agricultural Research 2(3): 115118.

4. Yadav CM, Chaudhary JL (2010) Effect of feeding protected protein on growth performance and physiological reaction in crossbred heifers. Indian J Anim Nutr 27: 401-407.

5. Shelke SK, Thakur SS Amrutkar SA (2011) Effect of pre partum supplementation of rumen protected fat and protein on the performance of Murrah buffaloes. Ind J Anim Sci 81: 946-950.

6. Bimrew A (2013) Potential of biotechnology in Animal Feed Improvement in Developing Countries. Biotech Article 02: 15-28.

7. Capper JL (2011) Replacing rose-tinted spectacles with a high-powered microscope: The historical versus modern carbon footprint of animal agriculture. Anim Front 1(1): 26-32.

8. Meyer MJ, Capuco AV, Ross DA, Lintault LM, Van Amburgh ME (2006) Developmental and nutritional regulation of the prepubertal bovine mammary gland: II. Epithelial cell proliferation, parenchymal accretion rate, and allometric growth. J Dairy Sci 89(11): 4298-4304.

9. Klusmeyer TH, Fitzgerald AC, Fabellar AC, Ballam JM, Cady RA, et al. (2009) Effect of recombinant bovine somatotropin and a shortened or no dry period on the performance of lactating dairy cows. J Dairy Sci 92(11): 5503-5511.

10. Connor EE, (2015) Invited review: Improving feed efficiency in dairy production: Challenges and possibilities. Animal 9(3): 395-408.

11. Ben Salem H, Nefzaoui A, Makkar HPS, (2007) Feed supplementation blocks for increased utilization of tanniniferous forages by ruminants. In: Feed Supplementation blocks. Urea-molasses multinutrient blocks: simple and effective feed supplement technology for ruminant agriculture. Makkar HPS, Sanchez M, Speedy AW (Ed) FAO Animal Production and Health Paper 164 pp 1-12.

12. Roland PV (2013) Recent Advances in the Application of Biotechnology in Animal Nutrition. University of Ghana 10361069.

13. Akinfemi A, OA, Doherty F (2009) Assessment of the nutritive value of fungi treated maize cob using in vitro gas production technique. Livestock Research for Rural Development 21(11).

14. Mc Sweeney CS, Dalrymple BP, Gobius PM, Kennedy PM, Krause DO, et al. (2000) The application of rumen biotechnology to improve the nutritive value of fibrous feedstuffs: preand post-ingestion. Liv Prod Sci 59: 265283.

15. Raeth Knight ML, Linn JG, Jung H (2007) Effect of Direct-Fed Microbials on Performance, Diet Digestibility, and Rumen Characteristics of Holstein Dairy Cows. J Dairy Sci 90(4): 1802-1809.

16. Ekinci MS, Martin JC, Flint HJ (2001) Expression of a cellulase gene, ce1A, from the rumen fungus Neocallimastix patriciarum in Streptococcus bovis by means of promoter fusions. Biotechnol Lett (24): 735-741.

17. Mc Donald P, Edwards RA, Greenhalgh JFD, Morgan CA, Sinclair LA et al. (2010) Animal Nutrition. Pearson Books.

18. Mc Guffey R, Richardson KLF, Wilkinson JID (2001) Ionophores for Dairy Cattle: Current Status and Future Outlook. J Dairy Sci 84: E194-E203.

19. Sarica SA, Ciftci E, Demir K, Kilinc, Yildirim Y, (2005) Use of an antibiotic growth promoter and two herbal natural feed additives with and without exogenous enzymes in wheat-based broiler diets. South African Journal of Animal Science 35(1).

20. Krause DO, Denman SE, Mackie RI, Morrison M, Rae AL, et al. (2001) Opportunities to improve fiber degradation in the rumen: microbiology, ecology and genomics. FEMS Microbiol Rev, 27(5): 663-693. 
21. Aye PA, Adegun MK (2010) Digestibility and growth in West African Dwarf sheep fed gliricidia-based multinutrient block supplements. Agriculture and Biology Journal of North America.

22. Rufino LM, Detman A, Gomes E, Santiago DÍ, Reis D WL, et al. (2016) Intake, digestibility and nitrogen utilization in cattle fed tropical forage and supplemented with protein in the rumen, abomasum, or both. Journal of Animal Science and Biotechnology 7:11.

23. Jerry W, William P (2014) Mineral and vitamin nutrition in ruminants. The Professional Animal Scientist 30(2):180-191.

24. Tien Le D, Duc H Chu, Ngoc Quynh Le (2016) Improving Nutritional Quality of Plant Proteins Through Genetic Engineering. Curr Genomicsv 17(3): 220-229.

25. Lazzarini I, Detmann E, Batista SC, Paulino MF, Valadares F, et al. (2009) Intake and digestibility in cattle fed low-quality tropical forage and supplemented with nitrogenous compounds. 38(10).

26. Scott P, Travis J, Donald B (2012) Use of Biotechnology to Increase Food Production and Nutritional Value. pp. 505-522.

27. Adeyemo SM (2013) Enzymatic Reduction of Anti-nutritional Factors in Fermenting Soybeans by Lactobacillus plantarum Isolates from Fermenting Cereals. Nigerian Food Journal 31(2): 84-90.
28. Malmuthuge N, Guan LL (2017) Understanding host-microbial interactions in rumen: searching the best opportunity for microbiota manipulation. Journal of Animal Science and Biotechnology 8(8).

29. Fernando SC, Purvis HT, Naja FZ, Sukharnikov LO, Krehbiel CR, et al. (2010) Rumen Microbial Population Dynamics during Adaptation to a High-Grain Diet. American Society for Microbiology 76(22): 7482-7490.

30. Selene Jarrett, Cheryl J, Ashworth (2018) The role of dietary fibre in pig production, with a particular emphasis on reproduction. Journal of Animal Science and Biotechnology 9: (59).

31. Bob T, Palmer H (2015) By-product Feed Ingredients for Use in Swine Diets. US Pork Center of Excellence (515): 2231-2641.

32. Alagawany M, Elhack ME, Farag MR, Shaheen HM (2018) The usefulness of oregano and its derivatives in poultry nutrition. World's Poultry Science Journal 74 (3): 463-474

33. Ryan J (2019) The dual-purpose chicken: The future of poultry farming. The poultry site.

34. Wheeler MB (2013) Transgenic Animals in Agriculture. Nature Education Knowledge 4(11): 1. 